\title{
UN MODELO DE ASCENSO SOCIAL EN LA ÉLITE COLONIAL LOS ARANDA SAAVEDRA EN EL BAJÍO NOVOHISPANO
}

\author{
AN EXAMPLE OF SOCIAL MOBILITY AMONG THE COLONIAL ELITE \\ CLASS THE ARANDA SAAVEDRA FAMILY IN THE BAJÍO REGION \\ OF NEW SPAIN
}

\section{José Luis Caño Ortigosa}

Universidad de Sevilla

jcano5@us.es

\section{Resumen}

En este trabajo se presenta un modelo de ascenso social y de integración en la élite colonial, a través de la investigación de algunos miembros destacados de la familia Aranda Saavedra asentados en el real minero de Guanajuato durante el siglo xviII. Se ejemplifican así, por medio de un estudio de caso, valores sociales de la América española, además de algunos de los métodos de obtención de prestigio, riqueza y poder que permitieron a ciertos individuos medrar en la compleja sociedad colonial.

Palabras clave: sociedad, Indias, Guanajuato, élite.

\begin{abstract}
In this work a new model of social promotion and integration in the colonial elite is presented. This model is based on the research of several prominent members of Aranda Saavedra's family settled in the mining town of Guanajuato in the eighteen-century. So, through the study of a particular case, values of the Spanish America and the methods to obtain prestige, wealth and power are exemplified.
\end{abstract}

Keywords: society, Indias, Guanajuato, elite.

\section{Información del artículo}

Recibido: 18 de enero de 2018.

Aceptado: 23 de agosto de 2018.

DOI: $10.22201 /$ iih.24486922e.2019.60.63141 


\section{INTRODUCCIÓN}

Es posible que resulte difícil imaginar la tristeza, y quizá también la ilusión, con la que en pleno siglo XVII una persona emprendía el camino de las Indias dejando atrás su pueblo, seguramente para siempre. En una sociedad de marcado carácter rural, agrario y, en general, muy carente de movilidad, iniciar un viaje de miles de kilómetros a través de los caminos de Castilla, de océanos, de lo que para ellos eran climas hostiles, geografías imposibles y gentes inverosímiles puede tildarse de valiente aventura. Quizá, como muchos antes lo han descrito, de desesperada huida por la vida. Y es que, más allá de aquellos grupos reducidos de marinos, mercaderes, funcionarios y frailes acostumbrados a viajar, con mentalidad más universalista, debemos recordar que la gran mayoría de los emigrados a América durante la modernidad eran gentes sencillas, de pequeños pueblos y con pocos recursos. O lo que es lo mismo, en el continente colonizado contaban, principalmente, con el capital que suponía su propia persona, sus habilidades, su lugar de nacimiento y su suerte.

Por tanto, cualquier factor que pudiera allanar la llegada y el establecimiento de esas personas en las poblaciones de destino era muy valioso. ${ }^{1}$ De hecho, es bien sabido que, para los españoles peninsulares, viajar a América se constituía en una de las oportunidades más evidentes de ascenso económico y social. No en vano únicamente por trasladarse al continente americano pasaban a incluirse en el grupo social de mayor prestigio, lo que no garantizaba el éxito, desde luego, pero sí constituía una importante ventaja comparativa.

Además, al hecho de ser peninsular podían añadirse otras ventajas. Estamos convencidos de que una de las de mayor importancia era la de contar con parientes o paisanos bien situados en el lugar de destino, dispuestos a ayudar. A la ventaja anterior podía sumarse otra de gran utilidad, como lo era el haber podido obtener previamente un cargo en la administración o en la Iglesia indiana. Si esto era así, el futuro podía emprenderse con un optimismo proporcional a la cuota de poder y de seguridad que acompañara a ese empleo. Por supuesto, después, una vez situado en las Indias, la consecución de mayor prosperidad dependía de las actuaciones llevadas a cabo, la suerte que se tuviera en ellas, las personas que componían

${ }^{1}$ Caño Ortigosa (2011, pp. 177-187). 
su espacio de sociabilidad, las pautas de comportamiento adoptadas y el acomodo a las costumbres locales.

Así pues, con este trabajo queremos presentar el camino que permitió a los Aranda Saavedra, originarios de la pequeña localidad de Puebla de Alcocer, en Extremadura, a situarse entre lo más granado de la alta sociedad guanajuatense, justo cuando ésta experimentaba el mayor esplendor económico de su historia. No queremos dejar de indicar que la elección del clan Aranda Saavedra no es casual, ya que la importancia que adquirieron durante la primera mitad el siglo XVIII ha sido puesta de manifiesto por destacados autores dedicados a la historia colonial guanajuatense, como Brading en su conocido trabajo sobre los mineros y comerciantes de esa localidad o Villalba Bustamante, entre otros. ${ }^{2}$ Pero nosotros, ahora, queremos profundizar en esos conocimientos iniciales, centrándonos en el estudio de los orígenes y de la estrategia de ascenso social que motivaron su éxito. Esos datos siguen siendo desconocidos para la historiografía guanajuatense, mexicana y americanista en general.

En consecuencia, este estudio se inserta en la línea historiográfica que busca una mayor y mejor comprensión del modo de actuar de las élites locales indianas, tanto en la búsqueda de su mejora social como del mantenimiento de su estatus. ${ }^{3}$ La mencionada línea parte del análisis de las pautas concretas de actuación de las personas y de las redes familiares y de sociabilidad que conformaban tales grupos, en un intento por averiguar cómo muchas de aquellas personas consiguieron acceder a los escalafones más elevados de la sociedad colonial y cómo lograron mantenerse en esa posición de privilegio ellos mismos y sus descendientes. Y es que es así, partiendo de ese conocimiento previo, como pueden identificarse mecanismos válidos de acción social que ayuden a explicar el actuar de esos colectivos específicos de la sociedad indiana.

Para lograr lo anterior, una herramienta útil es la técnica prosopográfica, ya que permite alcanzar pronto unas primeras conclusiones válidas sobre

2 Brading (1975, pp. 404-407); Villalba Bustamante (2015, URL: http://nuevomundo. revues.org/67764, consultado el 23 de octubre de 2017).

${ }^{3}$ Góngora (1970); Bott (1971); Boissevain (1974); Grendi (1977, pp. 506-520); Ginzburg y Poni (1979, pp. 181-204); González y González (1986 y 1997); Levi (1991); Ramón (1992); Gómez (1993, pp. 15-42); Revel (1996); Friedkin (1998); Dedieu y Moutoukias (1998, pp. 22-23); Schröter y Büschges (1999); Bertrand (2000, pp. 62-65 y 1999a, pp. 113117); García Bernal (2000, pp. 89-110); Moutoukias (2002, pp. 69-70); Caño Ortigosa (2005, pp. 77-92). 
esos grupos y las personas que los integraban. Así lo demuestra el éxito cosechado por diversos autores en numerosos trabajos americanistas, como Peter Marzahl en sus investigaciones sobre Popayán o los de Stephen Webre para Guatemala. ${ }^{4}$ Para el caso guanajuatense, tal metodología ya ha dado también su fruto cuando Caño Ortigosa dio a conocer el exitoso camino seguido por el leonés Agustín de la Torre y por el clan Septién Montero para prosperar en la sociedad guanajuatense del siglo XviII. ${ }^{5}$ Entendemos que el caso de la familia Aranda Saavedra en El Bajío durante los siglos XVII y XVIII se presenta como una clara muestra más de este tipo de empleo de mecanismos sociales que culminaron con su integración en la élite regional.

Tampoco queremos dejar de señalar que al hablar de élites indianas hacemos referencia a una parte de la sociedad bien distinguida de la restante, la que ya ha sido definida como la minoría rectora. Para identificarla nos apoyamos en unos sencillos principios teorizados y reducidos por Weber, como son la posesión de riqueza, de prestigio y de poder. Éste los utilizó para jerarquizar a la sociedad a partir de la acumulación que de ellos hicieran los distintos grupos sociales. ${ }^{6}$ Es decir, para poder señalar a una familia como parte de la élite colonial debemos identificar en ella la posesión, en mayor o menor medida, de cada uno de esos tres factores. No se nos escapa que, obviamente, los tres pueden aparecer por separado, pero también es cierto que a medida que se adquiere alguno de ellos los otros comienzan a sumarse y a interactuar entre sí, condicionándose recíprocamente. En unos casos desempeñaba un papel preponderante uno de ellos y, en otros casos, cualquiera de los restantes. De hecho, si bien en América comenzó a valorarse más, y más pronto, la acumulación de riqueza, debido a la aplicación mucho más laxa de los criterios estamentales, también es cierto que el prestigio que otorgaba el ser peninsular y el poder de los cargos obtenidos en la administración desempeñaban un papel fundamental a la hora de situarse en los distintos escalafones sociales. ${ }^{7}$ Sea como fuere, lo cierto es que poseer prestigio y poder facilitaba enormemente la obtención de riqueza, y a la inversa, como ya demostraron la escuela funcionalista y Wright Mills, por citar sólo algunos ejemplos que respaldan esta metodología. ${ }^{8}$

\footnotetext{
${ }^{4}$ Stone (1972, p. 107); Marzahl (1978); Webre (1989, pp. 189-219).

${ }^{5}$ Caño Ortigosa (2009a, pp. 107-126, y 2009b, pp. 1-15).

${ }^{6}$ Weber (1981, pp. 28-42).

${ }^{7}$ Flandrin (1979); Valmori, Voss y Wortman (1984).

${ }^{8}$ Mills (1987).
} 
Precisamente, en relación con la obtención de poder y prestigio, resultó un factor fundamental la implantación del sistema de venta de oficios a partir, esencialmente, de la bien conocida real cédula dictada para tal efecto en 1606. De esta manera, los poseedores de riqueza vieron facilitado su acceso a los otros dos elementos de ascenso social, produciéndose un enorme fenómeno de compra de cargos públicos. El ejercicio de estos cargos, a su vez, permitió una mayor acumulación de riqueza por parte de estos individuos y redes, toda vez que los desempeñaron, sobre todo, en su propio provecho a través de la corrupción y el uso y abuso de la información privilegiada y del poder que sus puestos les otorgaban. En este sentido tampoco debe olvidarse que la enajenación de cargos por parte de la Corona conllevaba, en la mayor parte de los casos, la posibilidad de traspasar el oficio a familiares o allegados como un patrimonio más, con lo que se conseguía la permanencia en el tiempo de la red familiar o clientelar construida. Unas ventajas que los Aranda supieron explotar, como veremos, por medio del acceso a distintos cargos municipales y, en especial, con la obtención en propiedad de la Alcaldía Provincial de la Santa Hermandad de Guanajuato.

Por último, como es bien conocido, otro relevante poder que actuó en las colonias fue el espiritual, lo que motivó que éste también fuera utilizado por miembros de las élites indianas. No extraña, pues, que individuos de la familia Aranda Saavedra ocuparan puestos eclesiásticos y que, de hecho, fueran utilizados en beneficio del clan para su ascenso y mantenimiento en la oligarquía abajeña. Esto se hacía más fácil una vez que se conseguía colocar bien a individuos de la familia dentro de la Iglesia, desde la que se podía tener mejor acceso a los censos eclesiásticos, eludir condenas en los juzgados por delitos contra la moral o la fe, recibir o administrar cuantiosas cantidades de dinero derivadas de donaciones y capellanías, etcétera.

Así pues, acumular riquezas, prestigio y poderes públicos y religiosos fue el objetivo de todos aquellos que aspiraban a pertenecer o mantenerse entre las élites de la América hispana en general y de Guanajuato y El Bajío en particular. Desarrollar una actividad económica lucrativa, disfrutar de importantes propiedades agropecuarias, ocupar un cargo de poder y pertenecer a la oficialidad del ejército regular o al clero conllevaba el respeto, la admiración y el reconocimiento de los vecinos. Precisamente, la consecución de todo lo anterior representaba la culminación de toda carrera personal hacia la cúspide de la sociedad colonial, cuyo último premio era 
la obtención de un título nobiliario o, al menos, emparentar con una familia que ya lo disfrutara. ${ }^{9}$

Y es en este último aspecto señalado donde pondremos especial énfasis en este trabajo, toda vez que sin tener que ir adquiriendo todos los elementos mencionados hasta ahora, una buena política matrimonial se mostraba como el camino más rápido para alcanzar los fines sociales anhelados. No obstante, ello tampoco era fácil, pues para poder casarse con alguien de superior consideración, o al menos poseedor de mayor riqueza o cualquiera de los demás elementos considerados, lo normal era pertenecer a la familia, en su carácter extenso, o formar parte de la red clientelar de la misma. ${ }^{10}$ Otra opción habitual era que el candidato ya poseyera riqueza, prestigio y poder en una cantidad suficiente o similar a la ostentada por la familia receptora, de manera que ésta tuviera el interés de ver aumentados sus recursos o añadir nuevos elementos a sus bases de sustento económico y social.

Es por todo ello que no resulta difícil ver cómo en las Indias un buen número de peninsulares aportaron el prestigio de su procedencia geográfica, sus recursos económicos o sus cargos en la administración a los más destacados clanes criollos a través del matrimonio con las féminas de estas familias. En tal sentido, sin duda, éste fue el instrumento fundamental utilizado por los extremeños del clan Aranda y que los llevó a acabar formando parte de la red familiar más poderosa del Guanajuato colonial. Lo que no deja de ser un nuevo ejemplo del éxito social que muchos peninsulares consiguieron en las distintas urbes americanas, por el hecho de serlo y de haber sabido mantener el contacto afectivo con sus familiares emigrados. A su vez, estas alianzas matrimoniales y las prácticas endogámicas permitían el afianzamiento de los grupos oligárquicos. El entronque de diferentes linajes, o de los mismos uniendo la rama peninsular y la americana, creaba finalmente una compacta red de parentesco y compadrazgo que aunaba intereses comunes. Tales fenómenos de creación de redes resultaron ser a lo largo del siglo XVIII, en algunos casos, un buen mecanismo de resistencia frente al empuje del creciente número de personas enriquecidas que reclamaban mayores cotas de poder y representatividad, política y social. Pero también un buen mecanismo de incorporación de

${ }^{9}$ Caño Ortigosa (2009a, pp. 107-111).

${ }^{10}$ Bertrand (1999b, pp. 35-51); Acosta Rodríguez (2000, pp. 153-154); Langue (1997, pp. 199-228); Castañeda (2005, pp. 17-28); Ponce Leiva (2006). 
estos nuevos actores sociales sin tener que renunciar a la destrucción completa de las redes ya formadas. ${ }^{11}$

No podemos aquí, obviamente, detenernos en elaborar un estudio comparativo o relacional, pero sí mencionar que son muchos los ejemplos conocidos que demuestran la utilización de este tipo de estrategia social entre las élites indianas que avalan la incorporación y la fácil ubicación de las redes oligárquicas guanajuatenses en ese mismo contexto colonial, del cual formaban parte y con el que interactuaban. ${ }^{12}$

Es más, el caso de las élites de El Bajío, y de Guanajuato en concreto, son especialmente idóneas para el estudio de los fenómenos explicados, tal y como se ha podido comprobar también en trabajos publicados con anterioridad. ${ }^{13}$ Pero en este caso se ha seleccionado como modelo explicativo a la familia probablemente más significativa de la alta sociedad guanajuatense de la primera mitad del siglo xviII, toda vez que los individuos protagonistas del estudio consiguieron incorporarse a la red más íntima y nuclear de quien llegara a conseguir el primer título nobiliario de la villa minera, el marqués de San Clemente y vizconde de Duarte. ${ }^{14}$

De esta forma, pretendemos que puedan iniciarse estudios comparativos entre los mecanismos utilizados por las distintas familias privilegiadas del principal real minero del imperio en aquel siglo y que puedan dilucidarse qué estrategias sociales, más endogámicas o flexibles, y económicas, más variadas o centradas en alguna actividad concreta, fueron más exitosas y la razón de ello. Asimismo, en extensión, adquirir ese conocimiento para una ciudad que vivía esencialmente de la actividad minera y situada en el

${ }^{11}$ Olveda (1988, pp. 15-23); Artís Espriú (1994); Bascary Peña (1994, pp. 117-120); Gonzalbo Aizpuru (1998, pp. 389-406); Boixados (1999, pp. 51-77); Flores Galindo (1984, pp. 59-69); García Bernal (1989, pp. 317-331).

${ }_{12}$ Mansilla (1941, pp. 103-110); Chinchilla Aguilar (1961); Cornejo (1972 y 1970, pp. 210-303); Blank (1979, pp. 90-115); Socolow (1980, pp. 387-406); Krüger (1981, pp. 3144); Corominas (1987); Uribe de Hincapié y Álvarez Gaviria (1988, pp. 51-93); Ferry (1991); Saguier (1992, pp. 211-266, y 1992, pp. 89-124); Broker (1993); García Giráldez (1994, pp. 145-164); Gil Blanco (1995, pp. 587-590); Ponce Leiva (1997, pp. 97-111); Casasola Vargas (1998, pp. 63-85); Rizo-Patrón Boylan y Aljovín de Losada (1998, pp. 241-293); Langue (1999 y 2000, pp. 104-115); Fogelman (2000, pp. 103-124); Rizo-Patrón Boylan (2000, pp. 241-293); Molina Martínez (2005, pp. 360-361); Valle (2006, pp. 23-48).

${ }^{13}$ Caño Ortigosa (2005, pp. 77-92, y 2009a, pp. 107-126).

${ }^{14}$ Caño Ortigosa (2011a, pp. 418-420). Para consultar la concesión del título de marqués de San Clemente, véase Archivo Histórico de la Universidad de Guanajuato (AHUg en adelante), Actas de Cabildo, 1721-1732: Título de marqués de San Clemente y vizconde de Duarte a favor de Francisco Matías Bustos Moya Jerez y Monroy, Sevilla, 20 de diciembre de 1730. 
centro del virreinato novohispano puede resultar muy útil a la hora de enfrentarlo con lo que ocurría en otras ciudades de características distintas en el mismo periodo de tiempo.

Situación inicial de los Aranda Saavedra

De partida, no es oportuno identificar como un fenómeno regular el que un recién llegado a las Indias, por el hecho de ser peninsular, estuviera destinado al éxito económico y social. Sin duda, por más que significara una ventaja comparativa, no necesariamente determinaba el éxito económico y social. Quienes lo conseguían fácilmente eran una excepción y una evidente minoría dentro de todos aquellos que emigraron a América buscando un mejor futuro para sí mismos. De hecho, lo más habitual era lograr el éxito aprovechando el campo abonado por familiares o paisanos llegados con anterioridad y cuya posición, iniciativa y trabajo había ya producido avances significativos.

Por eso se hace necesario indagar, tanto como sea posible, los orígenes de la presencia en la zona de miembros de la familia estudiada. Sólo así se podrá averiguar cuáles fueron los acontecimientos o los factores que facilitaron la mejora económica y social de los sujetos de estudio. Es decir, intentar dar respuesta a la pregunta: ¿cómo fue posible que unos individuos provenientes de un pequeño poblado cabeza de señorío como lo era Puebla de Alcocer, de unos 1000 habitantes a fines del siglo XVII, consiguieran convertirse en destacados mineros, mercaderes y miembros de la élite local y regional de la principal población productora de plata del mundo?

Por lo ya expuesto, la explicación debe iniciarse con los primeros Aranda que llegaron a la zona y ver de qué manera se dio su primera integración en la economía y la sociedad locales, analizando las posibilidades y las ventajas que disfrutaron con respecto a otros que también hubieran podido postularse para el ascenso social en la región. Como es lógico, cuanto más atrás en el tiempo e intentando descubrir avatares de personas menos destacadas se acrecientan las dificultades para reconstruir sus historias.

No obstante, podemos afirmar que algunos extremeños apellidados Aranda Saavedra ya estaban bien situados en América en la primera mitad del siglo XviI. Para afirmarlo debe adelantarse que fue necesario descubrir que esta familia se relacionaba estrechamente con el oficio de escribano, partiendo desde su población de origen en la península. En efecto, sabemos que en 
España, el duque de Béjar, que a la sazón era también señor de Puebla de Alcocer, confió algunas escribanías de poblaciones que estaban bajo su dominio a Juan de Aranda Saavedra, como en Capilla y en Hinojosa, en 1600 y 1625, respectivamente. ${ }^{15}$ Si tenemos en cuenta que era éste un oficio que garantizaba buenos dividendos y un excelente reconocimiento social, tampoco extraña que encontremos unos pocos años después a otro Aranda Saavedra de la familia siendo recomendado por el rey. ${ }^{16}$ Hasta en tres ocasiones entre 1634 y 1640 fue sugerido Bartolomé Aranda Saavedra para un puesto de escribano a los virreyes de Nueva España. Tampoco sorprenderá que otro miembro más de la familia, éste nacido en Belalcázar de Pedroche y llamado Juan Aranda Saavedra, consiguiera en 1641 la escribanía de la villa de San Miguel, en la alcaldía mayor de San Salvador de Guatemala, pagando 1000 pesos. Este último echó raíces en Nueva España, donde se casó dos veces; tuvo varios hijos, y ejerció también oficios de alcalde de la Santa Hermandad y síndico procurador. El de alcalde de la Santa Hermandad es un oficio que, al igual que el de escribano, desde los inicios veremos asociado habitualmente a las distintas actividades de la familia Aranda Saavedra. ${ }^{17}$

Así pues, hay una base suficiente para entender que en la región novohispana de El Bajío a mediados del siglo XVII, entre las décadas de 1650 y 1680, también encontremos a sujetos pertenecientes a este clan. ${ }^{18}$ Concretamente, la presencia en León de un tal Pedro Aranda, con un hijo de mismo nombre, dedicados a la cría de ganado destinado al abastecimiento de carne de aquella villa, en la que habían obtenido por remate el privilegio exclusivo de suministro de este producto básico. ${ }^{19}$

${ }^{15}$ Archivo Histórico de la Nobleza, Osuna, C. 355, D. 17 y C. 239, D. 81: Nombramientos de escribanos por el duque de Béjar, vizconde la Puebla de Alcocer, Madrid, 28 de enero de 1600; Testimonio del coste de una confección para el duque de Béjar, Madrid, 13 de agosto de 1625 .

${ }^{16}$ Archivo General de Indias (AGi en adelante), Indiferente General, 453, L.A.19, fs. 188189; L.A.17, fs. 50-51 y 454, L.A.23, fs. 48v-49v: Reales cédulas fechadas en Madrid, 22 de diciembre de 1636, 24 de mayo de 1634 y 27 de febrero de 1640, respectivamente.

17 AGI, Guatemala, 86, N. 10: Confirmación de oficio de escribano público de la villa de San Miguel, 28 de agosto de 1643. AGI, Guatemala, 90, N. 1: Confirmación y fiat de notario de Indias, 3 de febrero de 1667.

18 Archivo Histórico Municipal de León, Guanajuato (ahmL en adelante), Fondo Colonial, AM, Recursos Naturales y Forestales [RNF], Aguas [AGS], C. 1, exp. 8, 1651: León. Petrona de Puelles Villavicencio, viuda de Pedro Aranda, demanda al capitán Alonso de Aguilar porque éste le quitaba agua de riego de ella.

19 AHML, Fondo Colonial, AM, TSR, Rastro [RAS], C. 2, exp. 6, 1676, y exp. 7, 1680: León. Remates de abasto de carne en Pedro Aranda. 
Es decir, sea esa la primera o la segunda generación de los Aranda extremeños en llegar a la región, lo cierto es que prosperaron con la actividad ganadera hasta el punto de convertirse en los principales proveedores de una importante villa. Era una villa que, a su vez, era capital de la próspera alcaldía mayor homónima, bien situada en el camino real. Este hecho cobra especial relevancia cuando se advierte que los Aranda mantuvieron esta actividad como una de las bases más sólidas de todos sus negocios. Así, la rama que más prosperó del clan, la asentada en Guanajuato, también consiguió hacerse con el abasto de carne del real minero. Y lo que no resulta menos interesante es que fueron los primeros en conseguir en propiedad el título de alcalde de la Santa Hermandad de la villa minera, lo que les permitía proteger mucho mejor sus ganados en las tierras de la región.

Así, Juan Ignacio Aranda Saavedra aparecía en 1735 certificando el consumo de carne en Guanajuato para el expediente de solicitud del título de ciudad, que al ser de " 12000 carneros al año, 3400 reses, más las de las haciendas y minas, más todo lo que llega de carne salada”, hace imaginar el enorme volumen de negocio del que disfrutaba. Y ello después de que su padre hubiera conseguido en 1706 la propiedad del título de alcalde de la Santa Hermandad ya citado, un cargo que ya había ejercido por elección dentro del cabildo y al que no dejarían de estar vinculados miembros del clan durante décadas. Entre esos miembros puede citarse de manera especial al que luego sería marqués de San Clemente, lo que da muestras de la importancia del ejercicio de este puesto para los negocios de la familia. Asimismo denota una fuerte vinculación con el cabildo que, a su vez, permitía que el propio Juan Ignacio llegara a desempeñar en 1742 de forma interina el cargo de alcalde mayor del principal real minero del Imperio. ${ }^{20}$ Más tarde, sería Ramón Luis Aranda Saavedra el que ocupara el regimiento y la alcaldía de la Santa Hermandad, entre 1747 y $1754 .{ }^{21}$

Y es ahí donde eruditas consideraciones, como las de Villalba Bustamante, cobran todo su sentido. Como por ejemplo, la necesidad de identificación de aquellos individuos y familias que consiguieron mantener y hacer crecer sus negocios durante algunas décadas, hasta el punto de obtener los ingresos necesarios como para poder financiar a los empresarios

${ }^{20}$ Caño Ortigosa (2011a, pp. 62 y 373-375). AGI, México, 574: Expediente de confirmación del título de alcalde provincial de la Santa Hermandad a favor de Manuel Aranda Saavedra, 31 de octubre de 1709 .

${ }^{21}$ Archivo General de la Nación de México (agn en adelante), Ayuntamientos, 134, exp. 5. AHUG, PCL, 1749, 1750, 1751, 1754. 
motores de la región, los mineros, hacenderos y zangarreros. Por tanto, si el negocio de ganado de los Aranda era próspero y éste era un producto básico para el abastecimiento de las minas, se puede advertir la facilidad con la que pudieron llegar a invertir con dinero y animales en la producción metalúrgica o recibir acciones de minas a cambio de dicho abastecimiento. Este proceso bien pudo llevarlos a la asunción completa o mayoritaria de algunas minas en Guanajuato, tal y como los encontramos en fechas tempranas como 1696, cuando Manuel Aranda Saavedra se hacía cargo de Mina Rica y Mina Grande. ${ }^{22}$ Aún más fácil cuando se insertaron plenamente dentro de la élite política, económica y social de Guanajuato durante la primera mitad del siglo XviII.

Sea como fuere, los Aranda Saavedra de León siguieron manteniendo una distinguida situación en aquella villa, donde eran parte destacada de la élite local que se retroalimentaba para su permanencia como tal. A ello contribuyó muy probablemente el hecho de que siguieran manteniendo unos estrechos lazos con la rama guanajuatense de la familia, que llegaría a prosperar más que la originaria gracias a las facilidades económicas que ofrecía el real minero. Tales circunstancias pueden deducirse de la participación en León de miembros del clan, junto a los de otras significativas familias como los Obregón Alcocer y Septién Montero, como testigos en las necesarias comprobaciones de limpieza de sangre de personas destinadas a ocupar puestos de relevancia en la esfera local y regional. ${ }^{23}$

Ahora bien, ¿qué o quién pudo facilitar la inmersión de Manuel Aranda Saavedra en Guanajuato desde León donde se situaban los primeros negocios agropecuarios de la familia dirigidos por Pedro Aranda, padre, y Pedro Aranda, hijo? A esta pregunta pueden buscársele varias respuestas que, en sí mismas, pueden ser complementarias.

Así, sabemos que a finales del siglo xvir un tal Martín Aranda Saavedra ejercía en Sevilla de albacea y apoderado de miembros de la familia Flores Mogollón, quienes tenían situado a uno de ellos, Juan Ignacio Flores Mogollón, como tesorero en la Caja Real de Guanajuato, cargo que desempeñó entre 1689 y 1696 . Esta última fecha cobra especial importancia, pues es precisamente la misma en la que el tesorero de la Caja deja de estar en ese cargo antes de pasar a ser gobernador del Nuevo Reino de León y fecha

22 Villalba Bustamante (2015). URL: http://nuevomundo.revues.org/67764 [en línea], coloquios, puesto en línea el 10 marzo 2015, consultado el 16 de noviembre de 2017.

${ }^{23}$ AHML, Fondo Colonial, AM, Justicia [JTC], Averiguaciones [AVE], C. 1, exp. 28: Información sobre limpieza de sangre de Pedro de Cobos Arenal, vecino de Guanajuato, León, 1760. 
en la que hace su primera aparición documental en Guanajuato Manuel Aranda Saavedra. ${ }^{24}$

Aparte, como veremos más adelante, esta relación entre los Aranda y el tesorero de la Caja Real, y quizá por intermediación de éste, se extendió también al ensayador y balanzario de la Caja, Sebastián Romero Camacho, que ya lo era desde 1689 y permanecería en el puesto hasta $1725 .{ }^{25} \mathrm{~A}$ lo anterior puede añadirse que dos familiares peninsulares de la generación de aquel Pedro Aranda, "hijo", que bien podrían ser primos de éste, eran presbíteros y aparecen ejerciendo sus labores eclesiásticas en la región en el tercer cuarto del siglo xvir. Uno de ellos en el real minero.

Con todo, por tanto, no es descabellado pensar la facilidad con la que pudieron entrar en reunión un sacerdote peninsular llegado a aquella villa y los miembros de las más lucidas familias de la localidad. Como se ha visto, era fácil que el presbítero pudiera llevar ya establecidos los contactos necesarios y las cartas de recomendación de sus parientes leoneses y peninsulares destinadas a los oficiales de la Caja Real u otras personalidades locales. De ese privilegiado contacto entre religioso y feligreses a la presentación de allegados como posibles candidatos solteros que pudieran aportar su procedencia peninsular al prestigio de los clanes guanajuatenses consolidados, sólo quedaba un paso. Resulta curioso cómo este mecanismo de integración fue puesto en práctica repetidamente, de forma que luego, en el siglo XVIII, los Aranda seguían recibiendo a familiares eclesiásticos de la península, como el presbítero Joaquín Aranda Ceballos. ${ }^{26}$

En definitiva, toda la variedad de situaciones que hemos venido expresando hasta ahora acerca de los distintos miembros del clan Aranda Saavedra en Nueva España, creemos que son las claves de la aparición en Guanajuato en el último cuarto del siglo xviI de los dos hermanos, Manuel y Gonzalo, recién llegados de Puebla de Alcocer a las Indias. Era una llegada bien acondicionada que pronto dio sus resultados, toda vez que en 1695 Manuel ya tributaba en Guanajuato, donde tenía arrendada una de las mejores haciendas de beneficio del real, la de "San Nicolás del Cubo", que incluía varias minas adscritas a ella. Este arriendo perduró hasta 1699, año

${ }^{24}$ AGI, Contratación, 980, N. 2, R. 2: Expediente de bienes de difuntos de Francisco Flores Mogollón, 1694. AGI, Contratación 5451, N. 88: Expediente de licencia de pasajero a Indias, 7 de julio de 1689. AGI, Contratación 5458, N. 3, R. 3: Expediente de licencia de pasajero a Indias, 17 de julio de 1698. AHUG, PCL, 1696, ff. 190 y 198v.

${ }^{25}$ Caño Ortigosa (2005, pp. 77-92).

${ }^{26}$ AHUG, PCL, 1728, f. 205v: Escritura notarial, Guanajuato 8 de junio de 1728. 
en el que ya estaba en condiciones de matricularse como minero tras un lustro en el que había contribuido con sus impuestos a la Caja Real con casi 5000 pesos sólo en concepto de distintos ramos de impuestos asociados a la actividad minera. Esto hace imaginar que entre oro y plata Manuel consiguió extraer metales por un valor cercano a los 50000 pesos.

En efecto, Manuel Aranda Saavedra, recién iniciado el siglo Xvin se configuraba ya como miembro de la élite minera guanajuatense, donde podemos comprobar que supo manejarse con solvencia. Así lo corrobora el hecho de que mantuviera relaciones de negocios nada menos que con el ensayador y balanzario de la Caja Real de la villa, encargado de dar valor a toda la plata y oro que se producía en las entrañas de aquellas montañas. Pero Manuel no sólo supo acercarse a las personas adecuadas, sino también actuar con ellas en función de los mejores intereses para todos. Tal extremo lo atestigua el que en 1700 donara a los hijos del ensayador la mitad de dos minas en plena producción, la Doña María y la de Ponce, garantizándose el buen trato del oficial, mientras que éste a través de la propiedad de sus hijos se podía permitir explotar su propia plata sin que las leyes pudieran negárselo al no ser suyas en titularidad directa. ${ }^{27}$

\section{Los Aranda SE CONSOlidan en Guanajuato}

La excelente estrategia de relaciones económicas y sociales establecidas por los Aranda en Guanajuato pronto dio sus frutos, quizá más de lo que ellos mismos podrían haber esperado. Tan sólo un año después del episodio de la donación de minas a los hijos del ensayador, Manuel conseguía entablar el compromiso de boda con quien vendría a ser llamada una de las mujeres más influyentes de la historia de aquella población, Josefa Teresa Bustos Moya. Este compromiso fue adquirido ante notario con sus futuros suegra y cuñado. ${ }^{28}$ De esta forma, también, se seguía conservando la política matrimonial establecida por las mujeres de las principales familias guanajuatenses, a través de la red matriarcal que aseguraba el mantenimiento y el desarrollo de las propiedades dentro de los clanes emparentados, a

27 AGN, General de Parte, 18, exp 179, f. 175v-177: Licencia al Alférez Sebastián Romero Camacho, ensayador de Guanajuato, México 24 de septiembre de 1700.

${ }^{28}$ AHUG, PCL, 1701, f. 92v: Poder para casarse que otorgan Francisca Moya Monroy y Andrés Bustos Moya. 
la vez que un refresco continuado de sangre peninsular por medio de la elección de los candidatos más oportunos en cada momento. ${ }^{29}$

Tal matrimonio concertado no sólo introducía a Manuel en la más destacada familia guanajuatense de esos momentos, sino en toda la red del clan. Es decir, se le abría un mundo de posibilidades en el real minero, pero también para el desarrollo de los negocios de los Aranda en el resto de las poblaciones de la región. No en vano, su propia suegra, por ejemplo, vivía en la vecina ciudad de Querétaro. Asimismo, dentro de la red también muy pronto comenzó a ejercer roles que lo avalarían como un fiable pilar del clan, como lo atestigua el hecho de que fuera nombrado heredero y albacea en numerosas ocasiones por distintos miembros de la red familiar, haciéndose responsable de importantes cantidades de dinero. ${ }^{30}$

No extraña pues que, desde su matrimonio en 1701, Manuel disfrutara de una acomodada posición administrando los bienes de su esposa, los suyos propios y haciendo negocios desde una inmejorable posición social y clientelar. Prueba de todo ello son estipendios como la fundación de una capellanía en 1707, o las donaciones hechas a la parroquia de Santiago en su pueblo de origen, Puebla de Alcocer. ${ }^{31}$ Podía permitirse estas acciones altruistas gracias a los elevados ingresos de los que disfrutaba, tal y como demuestra el hecho de que sólo en concepto de producción metalífera llegara a tributar a la Corona entre 1695 y 1729 más de 556000 pesos. Es decir, las ganancias de Manuel en el sector extractivo durante los primeros 35 años que estuvo registrado como minero pudieron superar fácilmente los tres millones de pesos. ${ }^{32}$

También es cierto que tal cantidad de metal lo obligaba, desde luego, a sostener distintas haciendas de beneficio que se encontraban entre las mejores del real, y cuyos arriendos no eran baratos, en las que separar los

${ }^{29}$ Para la importancia de la mujer y de la red matriarcal en Guanajuato, véase Caño Ortigosa (2011b, pp. 103-157).

${ }^{30}$ A modo de ejemplo: AHUg, PCL, 1702, f. 34v: Convenio de los herederos Francisco Bustos Jerez con Felipe Cabrera. AHUG, PCL, 1710, f. 97v: Pago de 3225 pesos de la herencia de Nicolás Bustos Jerez por parte de Manuel Aranda Saavedra a Francisco Matías Bustos.

${ }^{31}$ AHUG, PCL, 1707, f. 221: Fundación de capellanía por parte de Manuel Aranda Saavedra y Josefa Teresa Bustos Moya. AHUG, PCL, 1719-1720, f. 596v, y PCL, 1723, f. 329v: Donaciones de una lámpara de plata y de un censo redimible por parte de Manuel Aranda Saavedra a favor de las imágenes de la virgen del Carmen y del Rosario de la parroquia de Santiago de Puebla de Alcocer.

${ }^{32}$ AGI, Indiferente, 220, N. 85: Relación de méritos de Alfonso Aranda Saavedra, 3 de abril de 1730 . 
metales de la piedra. Este era el caso de la hacienda de beneficio "Molinero", que alquilaba por 1000 pesos al año. ${ }^{33}$ Aparte, obviamente, necesitó de haciendas de campo que le administraran los insumos agropecuarios indispensables, a la par que le reportaran el prestigio que otorgaba la posesión de latifundios dentro de una sociedad sustentada en valores relacionados con el arraigo a la tierra y la ganancia a través de la percepción de rentas. Por esa razón no extraña que muchos de ellos se autodenominaran en los documentos que firmaban como mineros, ganaderos y hacendados. Únicamente por citar algunos ejemplos que puedan añadir información a las ya conocidas sobre las posesiones de esta familia, se puede incluir el hecho de que Manuel tenía intereses de este tipo en haciendas situadas en las poblaciones vecinas de Silao y Querétaro, como en las denominadas "San Juan" y "Aguasbuenas". Una muestra es la hacienda de San Juan, cuyos beneficios prefirió parcelar y vender en 1724, obteniendo así capitales líquidos añadidos. ${ }^{34}$ Ese mismo año nombró también un administrador para la hacienda que poseía en Querétaro, llamada "El Zamorano". ${ }^{35}$

En efecto, como es bien sabido, fue muy frecuente que los mineros de la América colonial carecieran de liquidez en numerosas ocasiones a lo largo de su trayectoria profesional, un dinero indispensable para poder continuar con las necesarias inversiones que continuamente requerían las minas y, en definitiva, su actividad empresarial. Es fácil por ello que, haciendo un breve seguimiento de las escrituras de préstamos conservadas en los archivos de protocolos nos encontremos a Manuel Aranda solicitando créditos. Uno de ellos fue el que pidió en 1725 al también minero Pedro de Aguirre Acharán, mediante la hipoteca de una valiosa casa que había comprado en 1714. Pero, quizá, lo más interesante de estas escrituras sea la demostración que hacen de la actividad en red ejercida por los interesados, toda vez que, por ejemplo, dicho préstamo estuvo asociado también a la donación de los réditos del crédito a la Compañía de Jesús (de la que era muy devota la esposa de Manuel) y a la compra por parte de Aguirre Acharán de una

${ }^{33}$ AGN, General de Parte, 23, exp. 301, ff. 217-218: Orden del virrey a las justicias de Guanajuato, México, 5 de octubre de 1715.

${ }^{34}$ Archivo de Silao, Ficha 77, 1724, Silao, libro 1: Manuel Aranda Saavedra vende a Alejandro Jiménez el tributo anual que le corresponde de un préstamo y dos milpas situadas en la hacienda San Juan.

${ }^{35}$ AHUG, PCL, 1724, f. 349: Poder para administrar hacienda, Guanajuato, 24 de enero de 1724. AHUG, PCL, 1725, f. 125v: Carta de poder, Guanajuato, 18 de mayo de 1725. 
casa al cuñado de Manuel Aranda Saavedra y futuro marqués, Francisco Matías Busto, hermano de su esposa. ${ }^{36}$

Manuel tampoco dejó de estar presente en el negocio de prestamista, como muchos contemporáneos suyos en situación socioeconómica parecida. ${ }^{37}$ Así, Manuel era beneficiario de las rentas que generaban los préstamos que concedía en tiempos de fortuna minera, sin duda una buena manera de invertir los capitales adquiridos cuando éstos llegaban en rachas de abundancia. Empréstitos que concedía a otros ilustres vecinos de Guanajuato y de otras poblaciones circundantes, como el de 1000 pesos que le dio a Luis Solache, vecino de Salamanca, bajo aval de una de las mejores viviendas de la ciudad. Esta casa se situaba en la plaza mayor, adosada a la vivienda de Francisco Matías Busto, ya marqués de San Clemente. ${ }^{38}$

Todos estos negocios se complementaban con las actividades ejercidas en red por el resto de familiares, como las que mantenía un miembro del clan con un conocido comerciante gaditano bastante vinculado con ellos y con intereses en América. Este mercader era Tomás Ruiz de Apodaca, a quien le escribía reiteradamente un tal Miguel Aranda y Saavedra en los años cuarenta del siglo XVIII. ${ }^{39}$ No en vano, a pesar de que los intereses principales de los Aranda Saavedra en Guanajuato se asociaron a las actividades mineras y a las agropecuarias, como ya se ha visto, no fue poco común que también figuraran como comerciantes en algunos documentos. Una muestra de esta circunstancia la constituyen las dos escrituras que firmó Gonzalo un día de 1725, donde se declaraba a sí mismo, específicamente, como mercader. ${ }^{40}$

Así pues, en definitiva, esta primera generación de los Aranda Saavedra en Guanajuato supo hacerse un hueco entre lo más destacado de la sociedad local y beneficiarse de los negocios que pudieron establecer con esa élite y la del resto de la región. Con todo ello pudieron crear una sólida base con la que garantizar el futuro, al menos, de la siguiente generación.

${ }^{36}$ AGN, Ayuntamientos, 134, exp. 5: comprobantes del informe radical de rentas públicas, 1677-1793 (documento 9, 1725-1729).

${ }^{37}$ Caño Ortigosa (2009a).

${ }^{38}$ AHUg, Protocolo de Presos, fs. 41-42v: Provisión de venta de una casa en la plaza mayor Guanajuato, 17 de febrero de 1745 .

${ }^{39}$ AGI, Consulado, 399, N. 27, fs. 429-430, y Consulado, 400, N. 8, fs. 304-323: Cartas de Miguel Aranda Saavedra a Tomás Ruiz de Apodaca, fechadas en Madrid, 7 de julio de 1744, 9 de febrero de 1745 y 22 de febrero de 1746.

${ }^{40}$ AHUG, PCL, 1725, fs. 129v y 133: Escrituras notariales, Guanajuato, 22 de mayo de 1725. 


\section{LA SEGUNDA GENERACIÓN}

Efectivamente, una vez consolidada una buena posición social y económica, el siguiente paso era poder garantizar el mantenimiento de ese estatus, si no mejorarlo, de los vástagos del clan. En este sentido, se hacía muy evidente la diferenciación entre las prácticas a seguir con los hijos varones y con las féminas, como comprobaremos.

No cabe la menor duda de que la forma más habitual y efectiva de garantizar el futuro de las hijas durante el Antiguo Régimen fue a través de la política matrimonial, beneficiándolas a la vez con un capital transmitido en forma de dote. En el caso del matrimonio no fue raro el hecho de practicar la endogamia, asegurando que todas las propiedades en juego permanecieran dentro del mismo clan familiar o, en su defecto, de la misma red clientelar. Ejemplo de lo primero fue el enlace entre Antonio Jacinto Aranda Díaz Madroñero y su tía materna Josefa Antonia Bustos Marmolejo. ${ }^{41}$ Por su parte, la importancia de la utilización del mecanismo y costumbre de la dote ya han sido estudiados en el caso de la élite de Guanajuato del siglo XVIII, por lo que no abundaremos aquí en esta cuestión. ${ }^{42}$

Únicamente recordaremos que fueron numerosas, y muy dispares en el monto, las dotes otorgadas en Guanajuato durante aquella centuria. Y en este sentido cabe destacar, a lo que interesa al presente trabajo, que entre las de mayor cuantía se encontraron las vinculadas a los Aranda Saavedra. Tanto es así que Manuel dotó a sus dos hijas con la más que suculentas cantidades de 20000 , a una, y 20250 pesos a la otra, en sus matrimonios con Francisco Alipasolo y José Antonio Mendizábal en 1718 y 1729, respectivamente. Ya entre esas fechas, asimismo, Gonzalo Aranda Saavedra había recibido 12000 pesos de la dote de su esposa, sobrina de la esposa de Manuel, al casarse con ella en $1725 .{ }^{43}$ Dentro de este avance social que estamos describiendo en los Aranda, unas generaciones más adelante el matrimonio con algunas de las doncellas casaderas de la familia se hizo lo suficientemente atractivo para algunos pretendientes como para ofrecer arras por su casamiento, como le sucedió a Ignacia Simona Quintana Aranda,

${ }^{41}$ Caño Ortigosa (2011a, p. 419).

${ }^{42}$ Caño Ortigosa (2006, pp. 97-122).

${ }^{43}$ AHUG, PCL, 1718, f. 40v: Cartas de dote, Guanajuato, 26 de febrero de 1718. AHUG, $P C L, 1725$, f. 618v: Guanajuato, 5 de diciembre de 1725. AHUG, PCL, 1729-1730, f. 117: Guanajuato, 18 de marzo de 1729. 
nieta de Manuel y Josefa Teresa, a la que Francisco Moreno Flores prometió 6000 pesos por su compromiso. ${ }^{44}$

Para el caso de los varones de la familia que se decantaban por la carrera eclesiástica, que anulaba cualquier posibilidad de percibir la administración de las dotes de sus esposas, se acostumbró a fundar capellanías en su favor. Para ellos, la cuantía destinada a la capellanía, al menos a priori, era el factor determinante a la hora de fijar el estatus y las posibilidades económicas del beneficiario. Varios fueron los hijos de Manuel Aranda y Saavedra con vocación religiosa, por lo que fundó varias capellanías a lo largo de su vida. Pero quizá lo más interesante sea que también fundó una de 2000 pesos de capital en 1720 a favor del presbítero José de Bustos y otra a favor del capellán José Alfonso Aranda en 1726. Con ellas hacía alarde de su implicación en la red familiar y en pro del desarrollo de todos los miembros de ésta, no sólo de sus hijos. ${ }^{45}$

Todas éstas eran distintas maneras de adelantar cantidades que de otra forma habría que esperar a la muerte de los padres y familiares cercanos para recibirlas en herencia. También, desde luego, una forma de amparar a quienes tenían más necesidad, a quienes fueran preferidos por cualquier motivo dentro del clan o no pudieran estar entre los directamente favorecidos por las escrituras de testamento. De hecho, son los testamentos una de las principales fuentes de información para conocer esos mecanismos de auxilio, respaldo, protección y mejora de los restantes miembros de la familia por parte de los que iban dejando de pertenecer a este mundo.

Así se demuestra en los distintos poderes para testar que los diferentes Aranda Saavedra fueron dando a lo largo de sus vidas, y en los que queda constancia no sólo de los beneficiarios sino también de los miembros del clan en los que se depositaba la confianza. Así, entre 1726 y 1727 Manuel Aranda Saavedra, su sobrino Antonio Jacinto Aranda Díaz Madroñero y su yerno Francisco Alipasolo triangularon poderes para testar, siendo la heredera del sobrino su madre María Aranda Saavedra, hermana de Manuel y casada con el también extremeño Antonio Jacinto Díaz Madroñero. ${ }^{46}$ De la misma manera, entre 1730 y 1732 la hija de Manuel Aranda y su marido, María Antonia y José Antonio Mendizábal, dieron poder para testar

${ }^{44}$ AHUG, PCL, 1760, f. 429v: Escritura de arras, Guanajuato, 27 de octubre de 1760.

${ }^{45}$ AHUG, PCL, 1720, f. 601v. Fundación de capellanía, Guanajuato 8 de agosto de 1720. AHUG, PCL, 1726, f. 311: Fundación de capellanía, Guanajuato, 23 de enero de 1726.

${ }^{46}$ AHUG, PCL, 1726, f. 392v: Poder para testar, Guanajuato, 10 de junio de 1726. AHUG, PCL, 1727, f. 229: Poder para testar, Guanajuato, 1 de octubre de 1727. 
a Alipasolo, declarando heredero al propio Manuel mientras éste donaba su parte de la herencia paterna a su hermana Luisa María ${ }^{47}$ Sirva también de ejemplo el poder que para ese fin otorgó Gonzalo Aranda Saavedra a su hermano Manuel y al yerno de éste para que se hicieran cargo de formalizar la entrega de sus propiedades a Juana Aranda, o a los hermanos de ésta si ella muriera, cuando él falleciera. ${ }^{48}$ Por último, tenemos constancia de que esta práctica era generalizada en la familia, ya que en 1745 Vicente Ferrer, hijo de Manuel, daba este tipo de poderes también a su hermano Juan Ignacio y a sus tres cuñados Alipasolo, Juan Antonio Mendizábal y Francisco Marquina. Mientras que en 1753 Gonzalo Aranda hacía lo propio a favor de Ana Aranda, su sobrina, y de su esposa, sobrina a su vez de su hermano Manuel. ${ }^{49}$

Aunque quizá sea más relevante conocer la capacidad de arreglo que, en este sentido, tenía el clan cuando era difícil conciliar intereses opuestos dentro de su seno. En efecto, esto puede verse en el conflicto que se abrió en la familia una vez fallecida en 1729 la mujer del futuro marqués de San Clemente y cuñada de Manuel Aranda, Luisa Marmolejo. Como suele ser habitual la disputa estaba en relación con su testamento, pero ésta no llegó a mayores gracias al convenio establecido entre el marido de la finada y sus dos yernos e hijas. ${ }^{50}$

Sin duda, la red familiar funcionaba como una máquina bien engrasada en beneficio de todos. Así lo demostró Francisco Matías Bustos al renunciar a su cargo de regidor de la villa a favor de su yerno Antonio Jacinto Aranda Díaz Madroñero, quien era además hijo de su cuñada María Aranda Saavedra. Tal cesión la hizo Francisco justo antes de obtener el título de marqués, con lo que puede deducirse que se hizo una redistribución de cargos y privilegios entre la familia para que el mayor número de sus integrantes tuviera un mínimo de poder y de prestigio que hacer valer en beneficio del clan. ${ }^{51}$ Este tipo de práctica tuvo su continuación durante las siguientes décadas, como lo demuestra el hecho de que Ignacio Uribarren, casado con

47 AHUG, PCL, 1730, f. 72: Donación de herencia, Guanajuato, 27 de enero de 1730. AHUG, PCL, 1732, f. 221: Escritura notarial, Guanajuato, 7 de noviembre de 1732.

${ }^{48}$ AHUG, PCL, 1724, f. 45v: Poder para testar, Guanajuato, 11 de febrero de 1724.

${ }^{49}$ AHUG, PCL, 1745, f. 117v: Poder para testar, Guanajuato, 18 de junio de 1745 . AHUG, PCL, 1753, f. 63. Poder para testar, Guanajuato, 21 de abril de 1753.

${ }^{50}$ AHUG, PCL, 1729-1730, f. 386: Escritura de convenio, Guanajuato, 22 de septiembre de 1729.

${ }^{51}$ AHUG, PCL, 1729-1730, f. 183v: Renunciación de oficio capitular, Guanajuato, 4 de mayo de 1729. 
una sobrina de Josefa Teresa, renunciase a su puesto de regidor perpetuo y con asiento preeminente al del alférez real en 1747 a favor de Ramón Luis Aranda Saavedra, hijo de aquélla. ${ }^{52}$

Obviamente, la ayuda mutua, la acción coordinada de conjunto y la inteligente utilización de los recursos socioeconómicos y políticos de los que disponían, hicieron que el clan se asentara como uno de los más importantes de la región de El Bajío, permitiéndoles aumentar su prestigio y su poder. Esa elevación social del conjunto de la red tuvo, desde luego, su punto culminante con la obtención del título de marqués de San Clemente por parte de Francisco Matías Bustos. No es necesario señalar aquí las ventajas comparativas a nivel económico y de poder que se lograban al alcanzar un título nobiliario, y que permitieron al marqués acrecentar su riqueza e influencia considerablemente. Tanto es así que en sólo dos años tras alcanzar el título ya podía beneficiar a su hija Josefa Antonia, sobrina de Manuel Aranda y cuñada de Gonzalo Aranda, con 14000 pesos a descontar de la herencia. Una cantidad que administraría el marido de la beneficiaria, quien no era otro que el sobrino de Manuel y Gonzalo Aranda, hijo de la hermana de ellos, Antonio Jacinto Aranda Díaz Madroñero. ${ }^{53}$ Pero si esa cantidad adelantada a una de las hijas parece considerable, palidece ante los más de 40000 pesos que dio al año siguiente a otra de sus hijas, Francisca Anastasia, que era la que estaba casada con Gonzalo Aranda. ${ }^{54}$

Pero no debemos olvidar que los capitales más destacados los poseían las hermanas del marqués, Josefa Teresa y Ana Gertrudis, verdaderas herederas de la riqueza de los Bustos. Una familia extensa que, al igual que el resto de las principales de Guanajuato, practicaba la transmisión por vía femenina de los bienes garantes de la prosperidad familiar, como ya se ha indicado más arriba. ${ }^{55}$

No extraña entonces el hecho de que a la muerte de Manuel, su esposa se hiciera cargo también de los bienes dejados por éste a sus hijos, cuyo principal capital era la hacienda de Aguasbuenas, en Silao, valorada en casi 170000 pesos. Para poder ser curadora de los bienes de sus hijos, Josefa Teresa hubo de avalar esa administración, y es entonces cuando podemos comprobar que su patrimonio era marcadamente más valioso que el de su

52 AGN, Ayuntamientos, 172, exp. 4: Autos sobre la renuncia que Ignacio de Uribarren hizo del empleo de regidor y alcalde de Santa Hermandad de Guanajuato, 1747.

${ }^{53}$ AHUG, PCL, 1732, f. 43: Pago de herencia, Guanajuato, 16 de febrero de 1732.

${ }^{54}$ AHUG, PCL, 1733, f. 28v: Recibo de herencia, Guanajuato, 17 de febrero de 1733.

${ }^{55}$ Caño Ortigosa (2011b, p. 120). 
marido. Tanto es así que Josefa Teresa avaló la hacienda de Silao con la suya propia, la hacienda Zamorano, más otros abundantes caudales que incluían su hacienda de minas, las acciones que poseía en dos de las principales minas del real, la de Cata y la de Mellado, así como la opulenta casa de la familia en la calle Cerero. ${ }^{56}$

Pero, lógicamente, no fue sólo el hermano de Josefa Teresa quien consiguiera alcanzar una acomodada situación. De hecho, como ya se mencionó más arriba, el matrimonio Aranda Bustos aventajó a sus hijas con suculentas dotes, con las que lograron unos maridos que, a su vez, pronto se situaron en la élite capitular. Así, María Antonia Aranda casó con José Antonio Mendizábal, mientras que su hermana María Rafaela lo hizo con Juan Antonio Quintana. Pero a lo anterior debemos sumar que ambas también eran accionistas de las mismas dos ricas minas de las que era propietaria su madre, como consta en los testamentos que ambas formalizaron en $1732 \mathrm{y}$ 1736, respectivamente. ${ }^{57}$ Todo ello permitía a María Rafaela, por ejemplo, ser la propietaria pocos años más tarde de una importante hacienda agropecuaria en Silao, como lo era la nombrada Nuestra Señora de Guadalupe "La Laja", a la que le sacaba una renta anual de 400 pesos por arrendamiento más los réditos del préstamo de 2550 pesos en los que valoraba la cesión del ganado, aperos, casa y capilla de la misma hacienda. ${ }^{58}$

Pero si las féminas veían garantizado su futuro, también los hijos eran mejorados, sobre todo aquellos que elegían la vida eclesiástica, tal y como se destaca en las escrituras en las que aparecían como herederos. ${ }^{59}$ Quizá, el más destacado de ellos fuera Alfonso José Aranda, hijo de Manuel. Éste se benefició de los costosos estudios que le pudieron pagar sus padres en el Colegio Tridentino, primero, y en la Pontificia Universidad de la ciudad de México, donde llegó a doctorarse en Teología. Sus méritos académicos fueron presentados ante el Consejo de Indias en 1730, para solicitar una plaza de presbítero en la Iglesia Metropolitana de la capital novohispana, y en ellos se recordaba también su contribución con 1000 pesos para la celebración

56 AHUG, PCL, 1730, f. 287: Otorgamiento de testamento, Guanajuato, 6 de julio de 1730. AHUG, PCL, 1732, f. 343: Aceptación de poder, Guanajuato, 11 de enero de 1732.

${ }^{57}$ AHUG, PCL, 1732, f. 221: Escritura testamentaria, Guanajuato, 7 de noviembre de 1732. AHUG, PCL, 1736, ff. 117 y 335: Testamentos de María Rafaela Aranda Saavedra, Guanajuato, 13 y 22 de abril de 1736.

58 AHUg, Protocolo de Presos, fs. 58-61v: Escritura de obligación de pago, Guanajuato, 27 de febrero de 1745 .

${ }^{59}$ AHUG, PCL, 1748, f. 175v: Escritura de herencia a favor de los presbíteros Vicente Ferrer y Juan Ignacio Aranda Saavedra, Guanajuato, 20 de junio de 1748. 
de la coronación de Luis I. ${ }^{60}$ En cualquier caso, ya tuvo lugar Alfonso José de devolver los favores a la familia, y seguir actuando a favor de ella prácticamente como hacía la totalidad de sus integrantes. De esta manera, con su buena preparación y su mejor ubicación en la capital mexicana se pudo convertir en un perfecto apoderado de los Aranda y de los Bustos en la corte virreinal, a la vez que éstos no dejaban de obsequiarle. De hecho, uno de estos peculios que siguió recibiendo de sus padres fue la capellanía que fundaron a su nombre en 1739 , con 6000 pesos de capital. ${ }^{61}$

Caso parecido fue el de su hermano Miguel Ambrosio, que recibió estudios, la posibilidad de viajar a la península y acabar ejerciendo en Madrid de apoderado de la familia años más tarde. En este apartado, no queremos dejar de señalar que la calidad de vida que se le proporcionaba a los vástagos que estudiaban en México era lo suficientemente elevada como para poder comprar y hacerse acompañar de esclavos que les servían, como fue el caso de José Fernando Aranda Saavedra cuando aún era cursante del Colegio de San Ildefonso en $1756 .{ }^{62}$ No debe olvidarse que la presencia de esclavos domésticos en la sociedad guanajuatense estuvo bastante generalizada, y nadie con posibilidades dejaba de tenerlos y de utilizarlos, entre otras cosas para mostrar su capacidad adquisitiva y estatus social. ${ }^{63}$

Tampoco parece casualidad que aquel mismo año de 1739, otro hijo de Manuel y Josefa Teresa, presbítero también y llamado Vicente Ferrer, recibiera homólogo beneficio que su hermano Alfonso José, aunque en esta ocasión el otorgante fue otro hijo presbítero más del matrimonio, Juan Ignacio Aranda. No cabe duda de la participación de los padres en esta fundación, toda vez que se hacía sobre el capital de la hacienda Zamorano, que como ya sabemos era propiedad de Josefa Teresa. ${ }^{64}$ También estos dos hijos eclesiásticos supieron devolver a la familia los favores que recibían,

${ }^{60}$ AGI, Indiferente, 220, N. 85: Relación de méritos de Alfonso José Aranda, 1730. AGI, Indiferente, 221, N. 21: Relación de méritos de Alfonso Aranda Saavedra, 30 de noviembre de 1730. AGI, Indiferente, 251, N. 82: Relación de méritos de Alfonso Aranda Saavedra, 30 de noviembre de 1730 .

${ }^{61}$ AHUG, PCL, 1730, f. 116: Escritura de poder, Guanajuato, 18 de febrero de 1730. AHUG, PCL, 1739, ff. 186v y 192: Fundación de capellanía, Guanajuato, 10 de septiembre de 1739.

${ }^{62}$ AHUG, PCL, 1756, ff. 161 y 227: Escritura de poder, Guanajuato, 23 de julio de 1756, y escritura de compra de esclavo, Guanajuato, 29 de noviembre de 1756.

${ }^{63}$ Sirva a modo de ejemplo de esta práctica por parte del clan estudiado: Archivo de Silao, Catálogo, p. 35, libro 1, ficha 197: Compraventa de esclava a “Aranda”, Silao, 1729.

${ }^{64}$ AHUG, PCL, 1739, f. 241: Fundación de capellanía, Guanajuato, 10 de diciembre de 1739. 
como lo demostraron al hacerse cargo de cobrar las deudas que acumulaba su madre de un buen número de morosos en la ciudad de Querétaro, casi todas relacionadas con la misma hacienda Zamorano y otra denominada El Temporal. ${ }^{65}$ Aparte, debe recordarse que en Guanajuato no fue extraño durante el siglo XVIII ver cómo miembros de la Iglesia ocupaban cargos capitulares en el cabildo, lo que abrió las puertas a que éstos también pudieran desempeñar los puestos de regimiento y justicia cuando la red familiar lo considerara oportuno. El propio Juan Ignacio, de esta forma, llegó a desempeñar cargos en el cabildo guanajuatense, como el de regidor a partir de 1744, al renunciar el puesto en él su cuñado Juan Antonio Quintana. ${ }^{66}$

Así pues, a partir de todo lo expuesto en este ejemplo de caso, creemos que quedan explicados algunos de los mecanismos más utilizados en las Indias para conseguir el ascenso social, así como aquellos que servían para el posterior mantenimiento del estatus alcanzado. Tales prácticas, no obstante, deben ceñirse al contexto en el que se produjeron, esto es, el propio de una villa colonial de mediano tamaño en el siglo xviII, situada en el centro neurálgico de Nueva España y cuyo motor económico era la actividad minera. Todo ello dentro de la región de El Bajío, que se constituía como una de las principales áreas urbanas de América, bien integrada y en la que se reproducía gran parte de los modelos socioeconómicos y políticos del resto del imperio.

Por tanto, Guanajuato y sus élites se nos antojan como un laboratorio de análisis perfecto a la hora de discernir las pautas de comportamiento más frecuentes de los grupos rectores locales de la América española, al menos en ese tipo de contexto, muy distinto, eso sí, al de ciudades capitales, fronterizas o portuarias, por ejemplo. Esto último no es baladí, pues supone una comprensión mayor de los cimientos sobre los que se establecieron las principales relaciones sociales dentro de las élites locales coloniales, sus vínculos de dependencia y fidelidad, así como su capacidad y voluntad de integración de nuevos elementos, ajustados a sus patrones socioeconómicos o no.

De hecho, en el caso que nos ha ocupado, como era el ascenso social en las Indias por parte de peninsulares recién llegados, la mayor o menor permeabilidad a la inclusión de elementos peninsulares en las redes clientelares

${ }^{65}$ AHUG, PCL, 1742, f. 105v: Escritura de poder, Guanajuato, 25 de junio de 1742.

${ }^{66}$ AHUG, PCL, 1744, f. 36: Renuncia del cargo de regidor de Guanajuato, Guanajuato, 20 de febrero de 1744 . 
locales y regionales existentes en la América hispana sería, a la postre, muy influyente a la hora de fijar sus políticas en conflictos generalizados en los territorios indianos. Muestra de ello fueron las reivindicaciones criollas primero, y las luchas independentistas después. Unas luchas donde lo local, las acciones llevadas a cabo desde los distintos municipios manejados por este tipo de clanes familiares en muchos casos, adoptaron una notable importancia, como es bien conocido.

\section{BiBLIOGRAFÍA}

Acosta Rodríguez, A. (2000). "Las redes sociales, el poder y sus fundamentos", Anuario del IEHS, 15, 153-154.

Artís Espriú, G. (1994). Familia, riqueza y poder. Un estudio genealógico de la oligarquía novohispana. México: Centro de Investigaciones y Estudios Superiores en Antropología Social.

BASCARY PeÑA, A. M. (1994). Sobre doñas y criadas: mujer, ocupación y matrimonio en San Miguel de Tucumán a fines del periodo colonial (pp. 117-120). En J. A. García, L. Provencio Garrigós y J. J. Sánchez Baena (eds.), Familia, tradición y grupos sociales en América Latina. Murcia: Universidad de Murcia.

Bertrand, M. (2000). Los modos relacionales de las élites hispanoamericanas coloniales: enfoques y posturas, Anuario IEHS, 15, 62-65.

(1999a). La élite colonial en la Nueva España del siglo xviII: un planteamiento en términos de redes sociales (pp. 35-51). En B. Schröter y C. Büschges (eds.), Beneméritos, aristócratas y empresarios. Identidades y estructuras sociales de las capas altas urbanas en América hispánica. Frankfurt/Madrid: Vervuert-Iberoamericana.

(1999b). De la familia a la red de sociabilidad. Revista Mexicana de Sociología, 61, 2, 113-117.

Blank, S. (1979). Patrons, Brokers and Clients in the Families of the Elite in Colonial Caracas, 1595-1627. The Americas, 36, 1, 90-115.

Boissevain, J. (1974). Friends of Friends. Networks, Manipulators and Coalitions. New York: St. Martin's Press.

Boixados, R. (1999). Transmisión de bienes en familias de élite: los mayorazgos en La Rioja colonial. Andes, 10, 51-77.

Bотт, E. (1971). Family and Social Networks: Roles, Norms and External Relations in Ordinary Urban Families. New York: Free Press.

Brading, D. A. (1975). Mineros y comerciantes en el México borbónico (1763-1810). México: Fondo de Cultura Económica. 
Broker, J. R. (1993). Veracruz Merchants, 1770-182: A Mercantile Elite in Late Bourbon and Early Independent Mexico. Boulder: Westview Press.

Caño Ortigosa, J. L. (2011a). Cabildo y círculos de poder en Guanajuato (16561741). Sevilla: Universidad de Sevilla.

(2011b) Guanajuato en vísperas de la Independencia: la élite local en el siglo XVIII. Sevilla, Universidad de Sevilla/Universidad de Guanajuato.

(2009a). El acceso al poder en Guanajuato: la familia Septién Montero (pp. 107-111). En M. C. García Bernal y S. F. Olivero Guidobono (coords.), El municipio indiano. Relaciones interétnicas, económicas y sociales. Sevilla: Universidad de Sevilla.

(2009b). El ascenso en la élite colonial novohispana: un leonés en Guanajuato". Temas Americanistas, 21, 1-15.

(2006). Las redes de poder en Guanajuato a través de la dote femenina y el matrimonio (1606-1821) (pp. 97-122). En N. Siegrist y E. O. Samudio A. (coords.), Dote matrimonial y redes de poder en el Antiguo Régimen en España e Hispanoamérica. Mérida, Venezuela: Universidad de los Andes.

(2005). El poder económico en Guanajuato: un caso de integración en la élite local (pp. 77-92). En L. Navarro García, Élites urbanas en Hispanoamérica. Sevilla: Universidad de Sevilla.

Casasola Vargas, S. P. (1998). La élite urbana de Santiago de Guatemala, 16321775: un estudio de redes. Revista de Historia, 38, 63-85.

CAstañeda, C. (2005). Historiografía de las élites en la Nueva España (pp. 17-28). En L. Navarro García (coord.), Élites urbanas en Hispanoamérica (De la conquista a la independencia). Sevilla: Universidad de Sevilla.

Chinchilla Aguilar, E. (1961). El ayuntamiento colonial de la ciudad de Guatemala. Guatemala: Universidad de San Carlos de Guatemala.

Cornejo, A. (1972). Genealogías de Salta. Los Fernández Cornejo. Salta: Imprenta de Artes Gráficas.

(1970). Abogados de Salta (Datos biográficos). Revista del Instituto de Historia del Derecho, 21, 210-303.

Corominas, J. (1987). Matrimonios de la Catedral de Tucumán, 1727-1765. Buenos Aires: Fuentes Históricas y Genealógicas Argentinas.

Dedieu, J.-P., y Moutoukias, Z. (1998). Introduction. Approche de la théorie des réseaux sociaux (pp. 22-23). En J. L. Castellano y J.-P. Dedieu (coords.), Réseaux, famillas et pouvoirs dans le monde ibérique à la fin de l'Ancien Régime. París: Centre National de la Recherche Scientifique.

FErry, R. J. (1989). The Colonial Elite of Early Caracas. Formation and Crisis 15671767. Berkeley: University of California Press.

Flandrin, J.-L. (1979). Orígenes de la familia moderna. La familia, el parentesco y la sexualidad en la sociedad tradicional. Barcelona: Crítica. 
Flores Galindo, A. (1984). Aristocracias y plebe, Lima, 1760-1830: (estructura de clases y sociedad colonial). Lima: Mosca Azul.

Fogelman, P. (2000). Elite local y participación religiosa en Luján a fines del periodo colonial. La cofradía de Nuestra Señora del Rosario. Cuadernos de Historia Regional, 20/21, 103-124.

Friedrin, N. E. (1998). A Structural Theory of Social Influence. Cambridge: SAGE.

García Bernal, M. C. (2000). Las élites capitulares indianas y sus mecanismos de poder en el siglo XVII. Anuario de Estudios Americanos, LVII-1. Sevilla: Escuela de Estudios Hispano-Americanos, pp. 89-110.

(1989). La aristocracia en Yucatán (siglo XVII) (pp. 317-331). En América: encuentro y asimilación. Actas de las II Jornadas de Historiadores Americanistas. Granada: Diputación Provincial de Granada.

García Giráldez, T. (1994). Las redes familiares vascas en las instituciones coloniales de Guatemala (pp. 145-164). En F. J. Laviña Gómez y P. G. Jordán (coords.), Memoria, creación e historia: luchar contra el olvido. Barcelona: Universidad de Barcelona.

Gil Blanco, E. (1995). Élites y propiedad territorial en Venezuela (1760-1810). Notas de aproximación a sus fuentes: los comerciantes. Estudios de Historia Social y Económica de América, 12, 587-590.

Ginzburg, C., y Poni, C. (1979). Il nome e il come. Mercato storiografico e scambio disiguale. Quaderni Storici, 40, 181-204.

Gómez, T. (1993). La república de los cuñados: parentesco, familia y poder en la sociedad colonial. Santa Fe, siglo xviII. Politeia, 12, 15-42.

GóngORA, M. (1970). Encomenderos y estancieros. Estudios acerca de la constitución social aristocrática de Chile después de la conquista. 1580-1660. Santiago: Universidad de Chile.

Gonzalbo Aizpuru, P. (1998). La familia en México colonial: una historia de conflictos cotidianos. Estudios Mexicanos, 14-2, 389-406.

GonzÁlez y GonzÁlez, L. (1997). Otra invitación a la microhistoria. México: Fondo de Cultura Económica.

(1986). Invitación a la microhistoria. México: Fondo de Cultura Económica.

Grendi, E. (1977). Micro-Analisi e storia sociale. Quaderni Storici, 35, 506-520.

Hoberman, L. S. (1991). Mexico's Merchant Elite, 1590-1660. Durham: Duke University Press.

KRÜGER, H. (1981). Función y estructura social del cabildo colonial de Asunción. Jahrbuch für Geschiste von Staat, Wirtschaft und Gesellschaft Lateinamerikas, 18, 31-44.

LANGue, F. (2000). Las élites en América española. De la historia de las prácticas a las prácticas de la historia. Anuario del IEHS, 15, 104-115. 
(1999). Los señores de Zacatecas. Una aristocracia minera en el siglo XVIII novohispano. México: Fondo de Cultura Económica. (1997). Las élites en América colonial (siglos XVI-XIX). Recopilación bibliográfica. Anuario de Estudios Americanos, LIV-1, 199-228.

Levi, G. (1991). On Microhistory (pp. 91-119). En P. Burke (ed.), New Perspectives on Historical Writing. University Park: Pennsylvania State University Press.

Mansilla, M. (1941). Historia de la Casa de Videla. Buenos Aires: Fundación Mansilla, pp. 103-110.

Marzahl, P. (1978). Town in the Empire: Government, Politics and Society in Seventeenth Century Popayán. Austin, University of Texas Press.

Mills, C. W. (1987). La élite del poder. México: Fondo de Cultura Económica.

Molina Martínez, M. (2005). El cabildo de Cumaná a mediados del siglo XviII (pp. 360-361). En Luis Navarro García (coord.), Élites urbanas en Hispanoamérica (De la conquista a la independencia). Sevilla: Universidad de Sevilla.

Moutoukias, Z. (2002). Las formas complejas de la acción política: justicia corporativa, faccionalismo y redes sociales (Buenos Aires, 1750-1760). Jahrbuch für Geschichte von Staat, Wirtschaft und Gesellschaft Lateinamerikas, 39, 69-70.

OlvedA, J. (1988). El matrimonio y la estructura de la familia oligárquica de la Colonia. Revista Jalisco, 6-2, 15-23.

Ponce Leiva, P. (2006). Élites en la América hispana: balance bibliográfico (19922005). Chronica Nova, 32.

(1997). El poder informal. Mujeres de Quito en el siglo Xvir. Revista Complutense de Historia de América, 23, 97-111.

Ramón, A. de (1992). Santiago de Chile, 1541-1991. Historia de una sociedad urbana. Madrid: MAPFRE.

Revel, J. (1996). Jeux d'échelles. La micro-analyse à l'expérience. París: École des Hautes Études en Sciences Sociales.

Rizo-Patrón Boylan, P. (2000). Linaje, dote y poder. La nobleza de Lima de 1700 a 1850. Lima: Pontificia Universidad Católica del Perú.

Rizo-Patrón Boylan, P., y Aljovín de Losada, C. (1998). La élite nobiliaria de Trujillo de 1700 a 1830 (pp. 241-293). En S. O'Phelan Godoy e Y. Saint-Geours (comps.), El norte en la historia regional, siglos XVIII-XIX. Lima: Centro Francés de Estudios Andinos.

SAgUiER, E. R. (1992a). Esplendor y crisis de las elites patricias: la endogamia en el cabildo de Córdoba: los Allende: 1760-1790. Genealogía, 25, 211-266. (1992b). La lucha contra el nepotismo en los orígenes de las reformas borbónicas. La endogamia en los cabildos de Salta y Tucumán (1760-1790). Andes, 5, 89-124. 
Schröter, B. y Büschges, C. (eds.) (1999). Beneméritos, aristócratas y empresarios. Identidades y estructuras sociales de las capas altas urbanas en América hispánica. Frankfurt/Madrid: Vervuert-Iberoamericana.

Socolow, S. M. (1980). Marriage, Birth, and Inheritance: The Merchants of Eighteenth Century Buenos Aires. Hispanic American Historical Review, 60-3, 387-406.

Stone, L. (1972). Prosopography (pp. 107-140). En F. Gilbert y S. A. Graubard (eds.), Historical Studies Today. New York, Norton.

Uribe de Hincapié, M. T., y Álvarez Gaviria, J. M. (1988). El parentesco y la formación de las élites en la provincia de Antioquia. Estudios Sociales, 3, 51-93.

VAlle, L. C. del (2006). Geografía política y espacios de poder: acciones y reacciones del cabildo porteño en la época tardocolonial (1776-1810) (pp. 23-48). En H. R. Zapico (coord.), De prácticas, comportamientos y formas de representación social en Buenos Aires (siglos XVII-XIX). Bahía Blanca: Universidad Nacional del Sur.

VAlmori, D., Voss, S., y Wortman, M. (1984). Notable Family Network in Latin America. Chicago/Londres: The University of Chicago Press.

Villalba Bustamante, M. (2015). El gran potencial de los pequeños y medianos mineros de Guanajuato en la segunda mitad del siglo Xvin. En Nuevo Mundos Nuevos [en línea], coloquios puestos en línea el 10 de marzo de 2015. URL: http://journals.openedition.org/nuevomundo/67764; DOI: 10.4000/nuevomundo.67764, consultado el 26 de marzo de 2019.

Weber, M. (1981). La distribuzione della potenza all'interno della comunitá: clasi, ceti, partiti (pp. 28-42). En M. Weber, Economia e societá (edición paperback), 4. Sociología política. Milán: Comunidad.

Webre, S. (1989). Antecedentes económicos de los regidores de Santiago de Guatemala, siglos XVI y XVII: una élite colonial (pp. 189-219). En Stephen Webre (ed.), La sociedad colonial en Guatemala: estudios regionales y locales. La Antigua Guatemala: Centro de Investigaciones Regionales de Mesoamérica.

\section{SOBRE EL AUTOR}

José Luis Caño Ortigosa es doctor en Historia de América por la Universidad de Sevilla, posee también el grado de Master en Historia Latinoamericana por la Universidad Internacional de Andalucía y es licenciado en Geografía e Historia por la Universidad Hispalense. Actualmente es profesor del Departamento de Historia, Geografía y Antropología de la Universidad de Huelva. Ha sido profesor del Departamento de Historia de 
América de la Universidad de Sevilla en diversas ocasiones, después de una estancia como Postdoctoral Research Fellow en la National Tsing Hua University (Taiwán) en 2016. Ha trabajado también para otras universidades, como la University of Michigan (EUA) en Sevilla y en el programa universitario norteamericano Council International Educational Exchange. Aparte, ha sido Profesor Libre de la Facultad de Derecho y Ciencias Sociales y Políticas de la Universidad Nacional del Nordeste (Argentina) y profesor en Sevilla para el programa de las Universidades de North Carolina, Clemson y Ohio State University. Investigador en diversos grupos financiados y reconocidos en los Planes de I+D+I de España, Argentina y Taiwán, alguno de ellos reconocidos de Excelencia. Sus investigaciones, fundamentalmente sobre la historia institucional y social de la América colonial, así como de las relaciones históricas entre España, Filipinas y la isla de Formosa (Taiwán) durante la Edad Moderna, han dado como resultado numerosos libros y aportaciones a revistas científicas. Es secretario científico de la revista Temas Americanistas e integrante, asimismo, del consejo científico de otras prestigiosas revistas especializadas. 
